\title{
PENGARUH TRANSCUTANEOUS ELECTRICAL NERVE STIMULATION DENGAN DAN TANPA TERAPI LATIHAN TERHADAP NYERI DAN KINERJA FISIK PADA PENDERITA OSTEOARTRITIS LUTUT
}

\author{
Inge Jiemesha \\ Engeline Angliadi \\ Program Studi Ilmu Kedokteran Fisik dan Rehabilitasi \\ Fakultas Kedokteran Universitas Sam Ratulangi Manado \\ Email: inge.jiemesha@gmail.com
}

\begin{abstract}
Osteoarthritis (OA) of the knee is a chronic degenerative joint disease which causes disability affecting the quality of life. Its management may include pharmacological and nonpharmacological treatment. In the non-pharmacological treatment there are a variety of treatment options. This study aimed to prove the effect of Transcutaneous Electrical Nerves Stimulation (TENS) with and without exercise on pain and physical performance in patients with knee OA. There were thirty five patients with knee OA who met the inclusion criteria that visited the Medical Rehabilitation Department of Prof. Dr. R.D. Kandou Hospital. The samples were divided into 2 groups: TENS with exercise therapy and TENS without exercise therapy. Each group undergone their therapy for 6 weeks with a frequency of 2 times per week. Pain was measured by using the Numeric Rating Scale (NRS) and physical performance was measured by using the Timed-Up and Go test (TUG) and the Stair Climb Test (SCT). There were $91.4 \%$ females meanwhile overweight and obese patients were $34.3 \%$. The results showed that there were significant differences in pain and physical performance between before and after TENS with exercise $(P<0.001)$ as well as before and after TENS without exercise $(P<0.001)$. There was no difference in pain and physical performance between the two groups. Conclusion: TENS with and without exercise can reduce pain and improve physical performance in patients with knee osteoarthritis.
\end{abstract}

Keywords: knee osteoarhtritis, TENS, pain, physical performance

\begin{abstract}
Abstrak: Osteoartritis (OA) lutut adalah penyakit degeneratif sendi yang bersifat kronis dan menyebabkan disabilitas yang memengaruhi kualitas hidup penderita. Tatalaksana OA lutut terdiri dari farmakologi dan non-farmakologi dengan bermacam-macam pilihan terapi. Penelitian ini bertujuan untuk membuktikan pengaruh Transcutaneous Electrical Nerves Stimulation (TENS) dengan dan tanpa terapi latihan terhadap nyeri dan kinerja fisik pada penderita OA lutut. Sebanyak 35 penderita OA lutut lama maupun baru yang memenuhi kriteria inklusi, yang berkunjung ke Poliklinik Rehabilitasi Medik RSUP Prof Dr. R.D. Kandou dan bersedia mengikuti penelitian. Sampel dibagi menjadi 2 kelompok: diberikan TENS dengan terapi latihan dan yang tanpa terapi latihan selama 6 minggu dengan frekuensi 2 kali per minggu. Nyeri diukur dengan Numeric Rating Scale (NRS) dan kinerja fisik diukur dengan Timed-Up and Go test (TUG) dan Stair Climb Test (SCT). Dari hasil analisis 35 subyek penelitian didapatkan 32 orang $(91,4 \%)$ subyek wanita, serta indeks massa tubuh yang overweight dan obese sebanyak $34,3 \%$. Hasil uji perbedaan nyeri dan kinerja fisik sebelum dan sesudah TENS dengan terapi latihan memperlihatkan perbedaan bermakna $(P<0,001)$. Hasil perbedaan nyeri dan kinerja fisik sebelum dan sesudah TENS juga memperlihatkan perbedaan bermakna $(P<0,001)$. Pada hasil uji perbedaan nyeri dan kinerja fisik pada kedua kelompok didapatkan tidak terdapat perbedaan antara keduanya. Simpulan: TENS dengan dan tanpa terapi latihan dapat mengurangi nyeri dan meningkatkan kinerja fisik pada penderita osteoartritis lutut.
\end{abstract}

Kata kunci: osteoartritis lutut, TENS, nyeri, kinerja fisik 
Osteoartritis (OA) adalah penyakit degeneratif sendi yang bersifat kronis, dan merupakan penyebab disabilitas dan nyeri muskuloskeletal terbanyak. Lebih dari $80 \%$ manusia usia lanjut mengalami OA, wanita lebih banyak dari pria. ${ }^{1,2}$ Berdasarkan data Reumatologi di Indonesia, OA merupakan salah satu penyebab disabilitas. Terdapat 4,4 juta dari 200 juta penduduk yang mengalami disabilitas, sebagian besar akibat OA lutut; ${ }^{3}$ oleh karena itu diperlukan tatalaksana yang optimal baik terapi konservatif maupun operatif.

Terapi konservatif terdiri dari terapi farmakologi dan non-farmakologi yang diberikan pada penderita dengan OA lutut ringan hingga sedang., ${ }^{2,4}$ Terapi nonfarmakologi dapat berupa terapi latihan dan modalitas fisik. Terapi latihan direkomendasikan pada beberapa panduan tatalaksana pada penderita OA lutut. Terapi latihan diterapkan secara bervariasi yang meliputi latihan penguatan otot, latihan peregangan dan latihan lingkup gerak sendi lutut. Terapi latihan dapat mengurangi nyeri dan meningkatkan kekuatan otot, kemampuan fungsional dan memperbaiki psikologi penderita. $^{5,6}$ Pemberian modalitas fisik, berdasarkan rekomendasi Osteoarthritis Research Society International (OARSI) yaitu terapi panas, elektro-akupuntur dan transcutaneous electrical nerve stimulation (TENS). Menurut Asosiasi Terapi Fisik Amerika dapat juga diberiakn terapi magnet, ultrasound dan Low Level Laser Therapy (LLLT). ${ }^{7,8}$ Berbagai modalitas fisik ini dapat membantu mengurangi nyeri pada OA lutut dengan mekanisme kerja yang berbeda-beda. TENS, elektroakupuntur, dan LLLT terbukti dapat mengurangi nyeri pada pasien dengan OA lutut.

\section{METODE PENELITIAN}

Penelitian ini bersifat deskriptif dan analitik. Subyek penelitian ialah penderita OA lutut lama maupun baru yang kontrol maupun dirujuk ke Instalasi Rehabilitasi Medik RSUP Prof. Dr. R.D Kandou Manado sejak Maret hingga Mei 2014 yang memenuhi kriteria inklusi yakni OA unilateral dan bilateral, usia 45-65 tahun baik pria maupun wanita, skala nyeri NRS 4-6, foto polos lutut menunjukkan klasifikasi Kellgren Lawrence 1-3, tidak menggunakan analgetik dan terapi lain minimal 3 hari, dapat memahami dan mengikuti petunjuk mengenai latihan yang diberikan dan menandatangi informed consent.

Pasien dibagi menjadi dua kelompok yaitu TENS dengan dan tanpa terapi latihan. Terapi dilakukan selama 6 minggu, dengan interval 2 kali per minggu. TENS yang digunakan ialah $100 \mathrm{~Hz}$ dan $50 \mu \mathrm{s}$ selama 20 menit dengan pad terbuat dari self-adhesive ukuran $5 \times 5 \mathrm{~cm}$ yang diletakkan di lutut sebelah anteromedial dan anterolateral. Terapi latihan dilakukan dengan latihan isometrik sebanyak 3 repetisi selama 10 detik dan peregangan dilakukan 2 repetisi selama 30 detik pada masing-masing otot kuadriceps dan Hamstring. Nyeri diukur berdasarkan NRS dan kinerja fisik diukur berdasarkan stair climb test (SCT) dan timed-up and go test (TUG). Pengukuran ini dilakukan sebelum dan sesudah intervensi.

Variabel-variabel dianalisis dengan analisis komparatif sebelum dan sesudah terapi menggunakan uji t-berpasangan bila data menyebar normal dan uji Wilcoxon Signed Rank Test bila data tidak menyebar normal. Analisis komparatif dua jenis terapi dengan uji t-independent jika data menyebar normal dan uji Mann-whitney jika data tidak menyebar normal.

\section{HASIL PENELITIAN}

Subyek penelitian berjumlah 35 orang; 18 orang diberi TENS dengan terapi latihan, 17 orang diberi TENS. Dari 35 subyek ini wanita sebanyak 32 orang $(91,4 \%)$ dan indeks massa tubuh sebagian besar obesitas dan overweight masingmasing sebanyak 12 orang $(34,3 \%$ ) (Tabel 1 dan 2).

Perbedaan nyeri dan kinerja fisik sebelum maupun sesudah TENS dan terapi latihan menunjukkan adanya perbedaan bermakna $(P<0,001)$ (Tabel 3). 
Tabel 1. Karakteristik subyek menurut jenis kelamin

\begin{tabular}{lccc}
\hline $\begin{array}{l}\text { Jenis } \\
\text { kelamin }\end{array}$ & $\begin{array}{c}\text { TENS } \\
\text { +Terapi } \\
\text { latihan }\end{array}$ & TENS & Total \\
\hline Pria & 0 & 3 & $3(8,6 \%)$ \\
Wanita & 18 & 14 & $32(91,4 \%)$ \\
Total & 18 & 17 & $35(100 \%)$ \\
\hline
\end{tabular}

Tabel 2. Karakteristik subyek menurut indeks massa tubuh

\begin{tabular}{lccc}
\hline IMT & $\begin{array}{c}\text { TENS } \\
\text { +Terapi } \\
\text { Latihan }\end{array}$ & TENS & Total \\
\hline Normal & 5 & 6 & $11(31,4 \%)$ \\
Overweight & 7 & 5 & $12(34,3 \%)$ \\
Obesitas & 6 & 6 & $12(34,3 \%)$ \\
Total & 18 & 17 & $35(100 \%)$ \\
\hline
\end{tabular}

Tabel 3. Hasil uji perbedaan nyeri dan kinerja fisik sebelum dan sesudah TENS dengan terapi latihan

\begin{tabular}{llllll}
\hline \multicolumn{2}{c}{ Kemaknaan } & Rata-rata & Median & Simpangan & Baku \\
\hline \multirow{2}{*}{ Nyeri } & Sebelum & 5,22 & 5,00 & 0,732 & $P<0,001$ \\
\multirow{2}{*}{ Naik tangga } & Sesudah & 2,83 & 3,00 & 1,654 & \\
\multirow{2}{*}{ Turun tangga } & Sebelum & 11,75 & 11,03 & 3,680 & \\
\multirow{4}{*}{ TUG } & Sesudah & 8,64 & 8,17 & 2,400 & \\
& Sebelum & 14,23 & 13,79 & 5,430 & \\
& Sesudah & 9,90 & 8,76 & 3,440 & \\
& Sebelum & 10,23 & 10,06 & 2,080 & \\
& Sesudah & 8,69 & 8,85 & 1,450 & \\
\hline
\end{tabular}

Tabel 4. Hasil uji perbedaan nyeri dan kinerja fisik sebelum dan sesudah TENS dengan terapi latihan

\begin{tabular}{llllll}
\hline \multicolumn{2}{c}{ Kemaknaan } & Rata-rata & Median & Simpangan & Baku \\
\hline \multirow{2}{*}{ Nyeri } & Sebelum & 5,47 & 5,00 & 0,51 & $P<0,001$ \\
\multirow{2}{*}{ Naik tangga } & Sesudah & 3,12 & 3,00 & 1,11 & \\
\multirow{2}{*}{ Turun tangga } & Sebelum & 17,05 & 12,98 & 10,36 & \\
\multirow{4}{*}{ TUG } & Sesudah & 12,44 & 11,63 & 4,77 & \\
& Sebelum & 19,32 & 17,30 & 7,53 & \\
& Sesudah & 14,28 & 11,68 & 5,60 & \\
& Sebelum & 10,23 & 10,06 & 4,07 & \\
\hline
\end{tabular}

Tabel 5. Hasil uji perbedaan nyeri dan kinerja fisik pada kedua kelompok

\begin{tabular}{llllll}
\hline Kemaknaan & & Rata-rata & Median & Simpangan & Baku \\
\hline Nyeri & $\mathrm{T}+\mathrm{L}$ & 2,39 & 2,00 & 1,420 & $P=0,384$ \\
& $\mathrm{~T}$ & 2,35 & 2,00 & 1,057 & \\
Naik tangga & $\mathrm{T}+\mathrm{L}$ & 3,10 & 2,23 & 2,560 & $P=0,287$ \\
& $\mathrm{~T}$ & 4,60 & 1,72 & 1,720 & \\
\multirow{2}{*}{ Turun tangga } & $\mathrm{T}+\mathrm{L}$ & 4,31 & 2,75 & 3,500 & $P=0,462$ \\
& $\mathrm{~T}$ & 5,03 & 3,84 & 4,890 & \\
TUG & $\mathrm{T}+\mathrm{L}$ & 1,54 & 1,45 & 1,110 & $P=0,224$ \\
& $\mathrm{~T}$ & 3,17 & 1,99 & 3,840 & \\
\hline
\end{tabular}

Ket: $\mathrm{T}+\mathrm{L}=$ TENS dengan terapi latihan $; \mathrm{T}=\mathrm{TENS}$ 
Perbedaan nyeri dan kinerja fisik sebelum maupun sesudah TENS dan terapi latihan menunjukkan adanya perbedaan bermakna $(P<0,001)$ (Tabel 4$)$.

Perbedaan antara kelompok TENS dengan dan tanpa terapi latihan terhadap nyeri dan kinerja fisik menunjukkan tidak ada perbedaan nyeri dan kinerja fisik keduanya (Tabel 5).

\section{BAHASAN}

Berdasarkan karakteristik subyek penelitian didapatkan wanita $(91,4 \%)$ lebih banyak daripada pria (Tabel 1). Hal ini sesuai dengan prevalensi OA lutut yang lebih banyak pada wanita, penyebab hal ini hingga sekarang belum jelas namun dikaitkan dengan pengaruh penurunan kadar estrogen yang berfungsi sebagai proteksi tulang rawan. ${ }^{2,3}$ Pada distribusi berdasarkan indeks massa tubuh (Tabel 2) didapatkan sebanyak masing-masing 12 orang $(34,3 \%)$ dengan overweight dan obesitas. Overweight dan obesitas berisiko mengalami OA lutut karena pembebanan berlebihan pada sendi lutut yang berperan sebagai sendi weight-bearing. ${ }^{1,2}$ Selain itu, overweight dan obesitas ini tidak hanya membebani sendi lutut selama fase stance tetapi juga menyebabkan ketidaksejajaran pada sendi lutut saat berjalan. ${ }^{10}$

Hasil uji nyeri dan kinerja fisik sebelum dan sesudah TENS dengan dan tanpa terapi latihan keduanya menunjukkan perbedaan bermakna sesudah terapi. Keluhan yang paling banyak dialami penderita OA lutut ialah nyeri dan gangguan aktivitas kehidupan sehari-hari yang akan berpengaruh pada kinerja fisik. Selain akibat proses kerusakan kartilago yang memproduksi mediator inflamasi, pada OA lutut nyeri dihantarkan dari jaringan perifer ke kornu dorsalis medula spinalis. Serat saraf yang menghantarkan nyeri ialah serat saraf yang tidak bermielin yaitu serat saraf A-delta dan serat saraf $C{ }^{11}$ Iwamoto et al. mendapatkan bahwa efektivitas latihan untuk OA lutut dapat mengurangi nyeri dan meningkatkan fungsi fisik. ${ }^{4}$ Menurut Law et al., TENS efektif dalam mengurangi nyeri pada penderita OA lutut. $^{12}$

Keluhan lain pada OA lutut ialah gangguan aktivitas kehidupan sehari-hari yang mempengaruhi kinerja fisik. Menurut OARSI, penilaian kinerja fisik terbagi menjadi dua yaitu recommended set dan minimum core set. Pada penelitian ini diambil masing-masing 1 jenis indikator pengujian tersebut yakni SCT dan TUG. Tujuan SCT ialah untuk melihat kecepatan naik dan turun tangga berkaitan dengan gangguan aktivitas kehidupan sehari-hari yang sering dikeluhkan sedangkan $T U G$ bertujuan untuk mengetahui kemampuan ambulasi transisi yakni dari duduk ke berdiri, berbalik arah, dan duduk kembali. ${ }^{13}$ Penelitian oleh Doyle menunjukkan bahwa functional task training exercise dapat meningkatkan kemampuan mobilitas fungsional pada penderita OA lutut. ${ }^{14}$ Selain itu, menurut Afaf, TENS dengan latihan dapat mengurangi gejala pada penderita OA lutut. ${ }^{15}$

Hasil uji perbedaan nyeri dan kinerja fisik pada kedua kelompok menunjukkan TENS dengan dan tanpa terapi latihan keduanya dapat mengurangi nyeri dan meningkatkan kinerja fisik pada penderita OA lutut, namun jika diamati pada masingmasing tabel uji perbedaan kinerja fisik, berdasarkan perhitungan statistik didapatkan peningkatan kinerja fisik pada perlakuan TENS dengan terapi latihan lebih baik dibandingkan TENS (median yang lebih kecil menyatakan waktu lebih singkat). Menurut Hughes et al. yang mengukur kinematik saat naik dan turun tangga pada penderita OA lutut maximum knee flexion moment saat naik tangga lebih besar 6 kali dibandingkan saat turun tangga dan maximum knee flexion angle saat naik dan turun tangga hampir sama. ${ }^{16}$

\section{SIMPULAN}

TENS dengan dan tanpa terapi latihan keduanya dapat mengurangi nyeri dan meningkatkan kinerja fisik pada penderita OA lutut. 


\section{LIMITASI}

Pada penelitian ini tidak dilibatkan lingkup gerak sendi dan kekuatan otot dari subyek penelitian sehingga tidak dapat dinilai pengaruh terapi latihan terhadap keduanya.

\section{DAFTAR PUSTAKA}

1. Bennell K, Hinman R. A review of the clinical evidence for exercise in osteoarthritis of the hip and knee. Journal of Science and Medicine in sport. 2010;14: 4-9.

2. Silva A, Serrao $P$, Driusso $P$, Matiello $P$. The effect of therapeutic exercise on the balance of woman with knee osteoarthritis: a systematic review. Physical Therapy Department University Sao Carlos Brazil.

3. Soeroso J, Dans L, Amarillo M, Santoso G. Risk factors of symtomatic and asymtomatic osteoatrhritis of the knee. Folia Medica Indonesiana. 2005;41(2):118-29.

4. Iwamoto J, Sato Y, Takeda T, Matsumoto H. Effectiveness of exercise for osteoarthritis of the knee: A review of the literature. World Journal of Orthopedics. 2011;2(5):37-42.

5. Pisters MF, Veenhof $C$, van Meeteren NLU, Ostelo RW, de Bakker DH, Schellevis FG, et al. Long-term effectiveness of exercise therapy in patients with osteoarthritis of the hip or knee: A systematic review. Arthritis and Rheumatism. 2007;57:1245-53.

6. Fitzgerald K. Role of physical therapy in management of knee osteoarthritis. Curr Opin Rheumatol. 2004;16:143-7.

7. Braddom RL. Rheumatic diseases (Chapter 36). Physical Medicine and Rehabilitation (Fourth Edition). Philadelphia: Elsevier Saunders; 2011. Rheumatic diseases; p.776-7

8. Jamtvedt G, Dahm KT, Christie A, Moe RH, Haavardsholm E, Holm I, et al. Physical therapy interventions for patients with osteoarthritis of the knee: an overview of systematic reviews. Journal of the American Physical Therapy Association. 2008;88:123-36.

9. Bjordal JM, Johnson MI, Lopes-Martins RAB, Bogen B, Chow R, Ljunggren AE. Short-term efficacy of interventions in osteoarthritis knee pain. A systematic review and meta-analysis of randomised placebo-controlled trials. BMC Musculoskeletal Disorders. 2007;8:1-14

10. Egloff C, Hugle T, Valderrabano V. Biomechanics and pathomechanics of osteoarthritis. Swiss Medical Weekly. 2012;142:1-14.

11. Swift A. Osteoarthritis 1: Physiology, risk factors and causes of pain. Nursing practice review musculoskeletal. 2012;108(7):12-15.

12. Law P, Cheing G, Tsui A. Optimal stimulation frequency of transcutaneous electrical nerve stimulation on people with knee osteoarthritis. Journal rehabilitation medicine. 2004;36: 220-5.

13. Dobson F, Bennel $K$, Hinman R, Abbot H, Roos E. OARSI. Recommended performance-based tests to assess physical function in people diagnosed with hip or knee osteoarthritis. The University of Melbourne. Australia.

14. Doyle C. The effects of traditional strengthening exercises versus functional task training on pain, strength and fucntional mobility in the 45-65 years old adult with osteoarthritis. Dissertation and thesis. 2011.

15. Shaheen A, Ibrahim A. Effectiveness of physical therapy treatment on pain and physical functions in patients with osteoarthritis of the knee: comparative study of manual therapy, supervised exercises and electropuncture versus well-designed home exercise program. College of physical therapy. Cairo University.

16. Hughes C, Kaufman K, Morrey B, Morrey K, An K. Gait characteristic during stair climbing in adults with osteoarthritis of the knee. Mayo Clinic Foundation, Minessota. 